\title{
Localizing the Sustainable Development Goals to Accelerate Implementation of the 2030 Agenda for Sustainable Development
}

\author{
The Current State of Sustainable Development Goal Localization \\ in Asia and the Pacific
}

\author{
By Pytrik Dieuwke Oosterhof ${ }^{1}$
}

\section{Introduction}

For the third time since the adoption of the Sustainable Development Goals (SDGs), the international community gathered at the High-Level Political Forum on Sustainable Development (HLPF) at United Nations (UN) headquarters in New York during 9-18 July 2018. ${ }^{2}$ Representatives from government, civil society, local and regional governments (LRGs), private sector, academia, and other stakeholders join the HLPF every year to take stock of the progress made in achieving the SDGs. Implementation of the
2030 Agenda for Sustainable Development has been underway since 2015, and many countries have already defined national strategies, approaches, development plans, and institutional reforms toward achieving the SDGs. However, the need to accelerate implementing efforts was echoed during the HLPF 2018.

While implementation of the 2030 Agenda occurs primarily at the national level, SDG achievement depends strongly on progress made at the local level. So far, limited attention has

\footnotetext{
Pytrik Dieuwke Oosterhof is a senior policy analyst with over 15 years of experience in international cooperation, sustainable development, and capacity building. At the UN Secretariat in New York, she has been engaged since 2013 in the preparation, adoption, and implementation of the 2030 Agenda for Sustainable Development. Prior to joining the UN, she represented the International Federation of Red Cross and Red Crescent Societies to the UN—and earlier, the European Union (EU) institutions -in the areas of sustainable development, climate change, and disaster risk reduction. She also managed public sector reform programs for a number of countries at the European Commission in Brussels. In addition to her full-time work, she taught EU and international affairs at the Danish Institute for Study Abroad, affiliated with Copenhagen University in Denmark, and provided ad hoc capacity building support to governments on behalf of the European Commission.

2 The HLPF is the world's main platform on sustainable development. It is tasked with assessing progress, achievements, and challenges faced by developed and developing countries in the implementation of the SDGs. The HLPF meets (i) annually under the auspices of the UN's Economic and Social Council for 8 days, including a 3-day ministerial segment; and (ii) every 4 years at the head of state and government level under the auspices of the General Assembly for 2 days.
} 
The success of multilevel governance and coherent SDG implementation can be fostered by effectively integrating the SDGs into the mandates of institutions and promoting cross-sector collaboration at

all levels. been paid to subnational SDG implementation. However, a growing recognition of the need to localize the SDGs was witnessed at the HLPF 2018 , with a number of initiatives and discussions giving attention to the need to accelerate SDG implementation through increased efforts at the local level. Apart from the thematic review of SDG 11 ("Make cities and human settlements inclusive, safe, resilient and sustainable"), the first Local and Regional Authorities Forum as well as a multi-stakeholder meeting titled Local2030 were held. Furthermore, the world's first-ever voluntary local review was presented by New York City, marking it as the first city to report on SDG progress at the local level. ${ }^{3}$

In the wake of the growing recognition around the importance of bringing the SDGs to the local level, this governance brief elaborates on the concept of SDG localization and analyzes to what extent localization is considered in the implementation of the SDGs in Asia and the Pacific. Through the lens of policy coherence and a multilevel governance approach, the aim is to provide context to why and how effectively leveraging SDG localization is critical for achieving sustainable development by 2030. Drawing on the member state mechanism of Voluntary National Reviews (VNRs) (Box 3), the governance brief looks at localization initiatives highlighted by countries in the Asia and Pacific region and considers issues in need of specific attention for effectively localizing the SDGs.

\section{Multilevel Governance and Policy Coherence for Sustainable Development}

With the adoption of the 2030 Agenda in 2015, a series of opportunities and challenges have emerged for the global community. The 2030 Agenda is often referred to as an integrated and transformative agenda. Its universal character requires multiple levels of government to collaborate across sectors. With a strong emphasis on policy coherence and integration, the framework resolution "Transforming our world: the 2030 Agenda for Sustainable Development" states, "Governments and public institutions will also work closely on implementation with regional and local authorities, subregional institutions, international institutions, academia, philanthropic organizations, volunteer groups and others." 4 This global partnership is, among others, embodied in SDG 17 ("Strengthen the means of implementation and revitalize the global partnership for sustainable development"), target 17.14, which calls on countries to "enhance policy coherence for sustainable development" as a means of implementation (Box 1). The target speaks to the interconnectedness between the 17 SDGs and the benefits of synergetic actions among stakeholders and levels of government. The need for integrated, inclusive, and coherent approachesthat enhance horizontal coordination between sectors, and vertical integration between levels of government-also addresses one of the underlying principles of the 2030 Agenda of "leaving no one behind." Although the UN Member States endorsed their formal commitment to the 2030 Agenda and its principles, the reality of SDG achievement will to a great extent rely on the actual inclusion, contributions, and collaboration of all partners and levels of government.

Multilevel governance has been described as the decision-making system to define and implement public policies produced by a collaborative relationship either vertical (between different levels of government, including national, federal, regional or local) or horizontal (within the same level, e.g., between ministries or between local governments) or both." 5 The success of multilevel governance and coherent SDG implementation can be fostered, for instance, by effectively integrating the SDGs into the mandates of institutions and promoting cross-sector collaboration at all levels. This requires adjusting institutional structures, aligning decision-making procedures, and installing mechanisms that support the cross-cutting and integrative nature of the SDGs. ${ }^{6}$

\footnotetext{
3 In addition to New York City's voluntary local review, three Japanese cities presented a review at a side event at the HLPF 2018 (Box 3).

4 UN General Assembly. 2015. UN Resolution 70/1: Transforming our world: the 2030 Agenda for Sustainable Development. New York (para. 45).

5 P. Stephenson. 2013. Twenty years of multi-level governance: "Where Does It Come From? What Is It? Where Is It Going?" Journal of European Public Policy. 20 (6). pp. 817-837.

6 The UN 2018 World Public Sector Report elaborates on the policy coherence and multilevel governance approach. It (i) aims to inform efforts by countries to foster horizontal and vertical integration for the SDGs, (ii) illustrates how different types of interlinkages that exist among the SDGs can be addressed from an institutional perspective, and (iii) includes concrete examples on subnational governance. UN, Department of Economic and Social Affairs. 2018. World Public Sector Report 2018Working Together: Integration, Institutions and the Sustainable Development Goals. New York.
} 


\section{Box 1: Policy Coherence for Sustainable Development}

Achieving greater policy coherence for development was widely promoted by the Organisation for Economic Co-operation and Development (OECD) as well the Global Partnership for Effective Development Cooperation, which was established in Busan, the Republic of Korea in 2011. With the implementation of the Sustainable Development Goals, the concept of policy coherence as a crosscutting means of implementation has become increasingly important. For this purpose, the OECD identified eight key building blocks for policy coherence that are subject to implementation of the 2030 Agenda for Sustainable Development: (i) policy commitment and leadership, (ii) integrated approaches to implementation, (iii) intergenerational time frame, (iv) analyses and assessments of potential policy effects, (v) policy and institutional coordination, (vi) local and regional involvement, (vii) stakeholder participation, and (viii) monitoring and reporting.

Source: OECD. 2018. Policy Coherence for Sustainable Development 2018: Towards Sustainable and Resilient Societies. Paris.

The assumption that adequate multilevel governance is a prerequisite for successful SDG implementation can be traced back to the lessons learned from the implementation of the Millennium Development Goals (MDGs). As the first unified effort to frame international development priorities, the MDGs were mainstreamed at the national and subnational levels in a number of countries. However, in spite of many achievements, the lack of capacity of local stakeholders was identified as one of the key shortcomings in the delivery of the MDG targets. According to an assessment carried out by the United Nations Development Programme (UNDP) and the World Bank Group, the lack of skills and resources at the local and regional levels was a hindrance in reaching targeted populations in implementing the MDGs. ${ }^{7}$ These and other shortcomings suggest that increasing the role of LRGs, communities, and local stakeholders is essential for accelerating progress on the SDGs, in particular to meet the principle of "leaving no one behind" that the 2030 Agenda is built on.

\section{Localizing the Sustainable Development Goals}

SDG localization has been described as "the process of defining, implementing and monitoring strategies at the local level for achieving global, national, and subnational sustainable development goals." It includes "the process of taking into account subnational contexts in the achievement of the 2030 Agenda, from the setting of goals and targets, to determining the means of implementation and using indicators that measure and monitor progress."

The concept of localization is far from new. At the UN Conference on Environment and Development held in Rio de Janeiro in 1992, the UN adopted Local Agenda 21, which was a voluntary process that aimed to create local policies and programs that work toward achieving sustainable development. The process required local governments to consult with the local community, minority groups, and businesses and industrial organizations to, for instance, develop local environmental plans, policies, and programs. This consultation process was developed to enhance awareness raising as well as the formation of partnerships and technical exchange programs. As mentioned in the previous section, localization was also promoted in the context of the MDGs. The concept was, however, introduced well into the MDG implementation period and was highlighted as a core necessity during the midterm evaluation in 2008, which indicated that the achievement of the MDGs required ownership, local accountability, and the efforts of local institutions. ${ }^{10}$ Learning from these experiences, it is widely recognized

\footnotetext{
UNDP and World Bank Group. 2016. Transitioning from the MDGs to the SDGs. New York and Washington, DC.

8 UN Development Group. 2014. Localizing the Post-2015 Agenda: Dialogues on Implementation. New York. p. 6.

9 Global Taskforce of Local and Regional Governments, UNDP, UN-Habitat. 2016. Roadmap for Localizing the SDGs: Implementation and Monitoring at Subnational Level. Barcelona. p. 6.

10 UN. 2008. Highlevel event on the Millennium Development Goals. Committing to action: achieving the Millennium Development Goals. Background note by the Secretary-General. New York.
}

Increasing the role of LRGs, communities, and local stakeholders is essential for accelerating progress on the SDGs, in particular to meet the principle of "leaving no one behind." 


\section{Strong commitment \\ to SDG localization}

by national

\section{governments was} considered critical for

providing the legal frameworks as well as the institutional and financial capacity needed for localizing the SDGs. that achieving the SDGs strongly depends on local contributions and the capacities of LRGs.

The 2030 Agenda aims to address global challenges such as eradicating poverty, reducing inequalities, and achieving environmental sustainability. These challenges directly concern and impact local communities and LRGs, and their efforts can contribute to achieving the SDGs. Although responsibilities of LRGs vary across countries, LRGs are often in a strong position to identify and respond to the gaps and needs of successful SDG implementation. LRGs are often in charge of key policy areas such as education, health, transportation, waste management, urban and territorial planning, local economic development, social inclusion, and basic services. Because LRGs are in close proximity to citizens, they play an important role in understanding citizens' needs, identifying gaps and minority and vulnerable groups, and facilitating awareness around the SDGs. Furthermore, LRGs can play a key role in data collection and monitoring related to the Agenda. Hence, the process of bringing the SDGs to the local level and vice versa is ideally considered to be a top-down and bottom-up process that enhances vertical and horizontal policy coherence and thereby contributes to the transformative change that is embedded in the 2030 Agenda.

The 2030 Agenda directly and indirectly makes reference to subnational efforts and LRGs. All of the SDGs have targets that relate to the role of LRGs in terms of their responsibilities in basic service delivery as well as their ability to promote and integrate inclusive and sustainable territorial development. Two SDGs explicitly relate to SDG localization: SDG 16 ("Promote peaceful and inclusive societies for sustainable development, provide access to justice for all and build effective, accountable and inclusive institutions at all levels") and SDG 11 ("Make cities and human settlements inclusive, safe, resilient and sustainable"). The implementation of these goals requires effective, accountable, and participatory institutions, and places particular responsibility on LRGs. This is especially the case for SDG 11, which, as a standalone goal for sustainable cities and communities, recognizes sustainable urban and local development as a fundamental precondition of sustainable development. The implementation, monitoring, and reporting of SDG 11 therefore requires mechanisms at the national and local levels that ensure effective alignment of efforts.

The embodiment of localization in the goals and targets reflects considerations raised during the preparatory negotiations of the 2030 Agenda. To gain a better understanding for what localization would entail, the so-called "global conversation," which was initiated by the UN Development Group, included a "global consultation on localizing the SDGs." "11 The outcome of the consultation identified a number of aspects that were considered to be instrumental for SDGs localization. Among other things, it revealed that, apart from a multilevel governance approach and the critical role of LRGs, effective local governance can promote the inclusion of local stakeholders and create broadbased ownership, commitment, and accountability. Moreover, strong commitment to SDG localization by national governments was considered critical for providing the legal frameworks as well as the institutional and financial capacity needed for localizing the SDGs. Building on the consultation outcome, a partnership between UNDP, UNHabitat, and the Global Taskforce of Local and Regional Governments developed a methodology and toolbox that support the SDG localizing approach at the global, national, and local levels. Among other tools, a "Roadmap for Localizing the SDGs" was created to guide stakeholders in the process of SDG localization (Box 2). ${ }^{12}$

These efforts indicate how the concept of localization has been shaped, how it features in the 2030 Agenda, and how it is now considered critical for achieving the SDGs. Nevertheless, while the SDGs theoretically require actions at the local level, the practical process of SDG localization is still subject to a number of questions. So far, little evidence-based research has been carried out on SDG localization, and assessments have mainly been based on national SDG review reports such as the VNRs (Box 3), which provide a picture of how countries approach SDG implementation. ${ }^{13}$

11 UN Development Group. 2013. The Global Conversation Begins: Emerging Views for a New Development Agenda. New York.

12 Global Taskforce of Local and Regional Governments, UNDP, UN-Habitat. 2016. Roadmap for Localizing the SDGs: Implementation and Monitoring at Subnational Level. Barcelona.

13 Focusing on localization of the SDGS, LRG reports were prepared and presented by United Cities and Local Governments (UCLG) during the HLPF 2017 and HLPF 2018. UCLG. 2017. Local and Regional Governments' Report to the 2017 HLPF: National and Sub-National Governments on the Way Towards the Localization of the SDGs. Barcelona; and UCLG. 2018. Local and Regional Governments' Report to the 2018 HLPF-2nd Report: Towards the Localization of the SDGs. Barcelona. 


\section{Box 2: Sustainable Development Goal Localization Road Map}

There is no single approach to Sustainable Development Goal (SDG) localization. However, some strategies were defined by the Roadmap for Localizing the SDGs: Implementation and Monitoring at Subnational Level, which was developed jointly by the Global Taskforce of Local and Regional Governments, United Nations Development Programme, and UN-Habitat. These strategies include the following:

Awareness raising and/or advocacy. This includes, for example, involving existing and new platforms and using traditional and social media channels to reach out to all sectors of society, incorporating information on the SDGs in educational programs, and nominating SDG ambassadors.

Implementation. Local and regional governments (LRGs) must prepare to implement the SDGs in their communities by, for instance, conducting needs assessments to define priorities, engaging in cooperative governance to establish shared priorities, aligning local and regional plans with the SDGs, mobilizing local resources, building capacities for effective and responsive leadership promote ownership, and participating in development cooperation and peer-to peer learning.

Monitoring. At the national level, subnational data should be taken into account in evaluating and reviewing results of national plans. Localizing the follow-up of the 2030 Agenda for Sustainable Development entails developing a set of localized indicators, ensuring that information collected by LRGs is included in national monitoring and reporting, enabling participation of LRGs and stakeholders in the review of national plans, using SDG indicators to monitor and assess local and regional plans, and ensuring local achievements are recognized and part of the national SDG progress reports (e.g., the Voluntary National Reviews).

Source: Global Taskforce of Local and Regional Governments, UNDP, UN-Habitat. 2016. Roadmap for Localizing the SDGs: Implementation and Monitoring at Subnational Level. Barcelona.
In many Asia and

Pacific countries, rapid urbanization

puts pressure on the capacity of local communities.
When analyzing these VNRs, it appears that SDG localization is still absent in many national SDG planning, coordination, and implementation processes. In countries where localization efforts are undertaken, approaches vary widely due to factors such as country and local contexts, government structures, capacities, and awareness of the SDGs.

\section{Sustainable Development Goal Localization in Asia and the Pacific}

In the Asia and Pacific region, the concept of SDG localization is highly relevant. In many Asian and Pacific countries, rapid urbanization puts pressure on the capacity of local communitiesincluding for urban planning for public services and infrastructure-and the impacts of climate change and natural disasters have effects on local communities. The region faces rising inequalities among and within countries, as well as a growing aging population; and there is a clear need for safeguarding the basic needs of poor and vulnerable groups.
Across the region, SDG implementation efforts are ongoing. According to a recent report by the UN Economic and Social Commission for Asia and the Pacific, progress toward the SDGs is being made, but the region needs to accelerate the pace of change and reverse negative trends in several areas. ${ }^{14}$ The report states that satisfactory progress is being made in the area of poverty eradication (SDG 1) and the promotion of good health and well-being (SDG 3 ). However, at the current rate of progress, the report concludes that only SDG 4 ("Ensure inclusive and equitable quality education and promote lifelong learning opportunities for all") is expected to be met. The report calls for efforts to step up development reform, address widening inequalities, and strengthen environmental stewardship.

At the country level, progress on the SDGs is monitored and reported in the context of the "follow-up and review process." This process is largely based on the VNRs, which are carried out by countries to track progress on their respective SDG implementation (Box 3). Since the adoption of the 2030 Agenda in 2015, 24 Asia and Pacific

\footnotetext{
14 UN Economic and Social Commission for Asia and the Pacific. 2018. Asia and the Pacific SDG Progress Report 2017. Bangkok.

15 After the adoption of the 2030 Agenda, a framework to ensure the "follow-up and review" of the 2030 Agenda was agreed by the UN General Assembly. UN General Assembly. 2016. UN Resolution 70/A/684: Critical milestones towards coherent, efficient and inclusive follow-up and review at the global level. New York.
} 
When assessing the VNRs, the reports paint a mixed picture when it comes to SDG localization.

\section{Box 3: Voluntary National Reviews}

Voluntary National Reviews (VNRs) form a fundamental part of the follow-up and review framework of the 2030 Agenda for Sustainable Development. The 2030 Agenda encourages countries to "conduct regular and inclusive review of progress at the national and subnational levels, which are country-led and country driven" and states that reviews are "state-led, undertaken by both developed and developing countries, and shall provide a platform for partnerships, including through the participation of major groups and other relevant stakeholders." A set of common reporting guidelines and a handbook for the preparation of VNRs seek to support countries in conducting VNRs in alignment with the guiding principles around the follow-up and review process at all levels. Central to the reviews are the core principles of the 2030 Agenda such as universality, "leaving no one behind," integration, inclusiveness, and ownership. The VNRs allow countries to plan appropriate policies, structures, and processes, and to revise or install new national development plans for achieving the Sustainable Development Goals (SDGs). While national ownership constitutes a significant level of the review process, the 2030 Agenda encourages countries to "conduct regular and inclusive reviews of progress at the national and subnational levels." National and local authorities, civil society, and the private sector should therefore be at the core of the review process.

The VNRs are presented at the annual High-Level Political Forum for Sustainable Development (HLPF) alongside annual thematic reviews of the SDGs and the global SDG progress report prepared by the United Nations. Since the implementation of the 2030 Agenda in 2015, 111 countries have carried out VNRs. In many countries, local and regional governments take part in the VNR process. New York City carried out a voluntary local review in 2018, making it the first city to formally report at the HLPF. The review was modeled after the national guidelines, but it reported on the local progress made on the SDGs.

In the Asia and Pacific region, three city reports were launched and aimed to document the efforts of local authorities in Japan working to advance the SDGs in Shimokawa town (Hokkaido prefecture), Toyama city (Toyama prefecture), and Kitakyushu city (Fukuoka prefecture). The reports followed the handbook for the preparation of the VNRs and were presented at a side event during the HLPF in July 2018.

Source: UN General Assembly. 2015. UN Resolution 70/1: Transforming our world: the 2030 Agenda for Sustainable Development. New York. countries have carried out a VNR. ${ }^{16}$ In 2016, these were Georgia, the People's Republic of China (PRC), the Philippines, the Republic of Korea, and Samoa. In 2017, Afghanistan, Azerbaijan, Bangladesh, India, Indonesia, Japan, Malaysia, Maldives, Nepal, Tajikistan, and Thailand carried out a VNR. In 2018, Armenia, Australia, Bhutan, Kiribati, the Lao People's Democratic Republic (Lao PDR), Singapore, Sri Lanka, and Viet Nam were among the VNR countries reporting at the HLPF. Drawing on the VNR reports, the following section on "National Plans and Framework Legislation Involving Sustainable Development Goal Localization" includes selected examples that illustrate where and how SDG localization takes place in the Asia and Pacific region. ${ }^{17}$
When assessing the VNRs, the reports paint a mixed picture when it comes to SDG localization. Offering a perspective of countries' approaches to, and progress made on their SDG implementation, the VNR reports describe the national SDG strategies, plans and frameworks, consultation processes, and other relevant steps in implementing the 2030 Agenda.

With regard to localization, about half of the 24 Asia and Pacific countries that carried out a VNR involved LRGs in their VNR consultation processes. Moreover, $31 \%$ of the countries in the region have engaged LRGs in their national coordination mechanisms and follow-up processes. ${ }^{18}$ In countries that report on SDG localization efforts, however, approaches vary significantly. Some include LRG

16 In 2016, 22 countries reported; in 2017, 43 countries reported; and 47 countries reported at the HLPF in July 2018.

17 The examples highlighted were featured in VNR reports completed during 2016-2018.

18 UCLG. 2018. Local and Regional Governments' Report to the 2018 HLPF-2nd Report: Towards the Localization of the SDGs. Barcelona. 
participation in the VNR consultation processes, assessments, and (in some cases) planning for national and/or local strategies. Some of the reports highlight proactive initiatives that support the integration of the SDGs through involving local government associations and parliaments in awareness-raising campaigns, advocacy efforts, and assessments. Furthermore, initiatives that build local capacities, and examples of local governments that independently have taken the lead on SDG implementation, were reported. Cities, in particular, are making progress in designing and implementing policies, plans, and projects that enhance sustainable development.

\section{National Plans and Framework Legislation Involving Sustainable Development Goal Localization}

While some Asia and Pacific countries recognize the need for SDG localization, only a few reported on a comprehensive holistic approach to bringing the SDGs to the local level. Countries that mention (i) localization in national plans, (ii) concrete mechanisms, or (iii) framework legislation include Australia, Bangladesh, Indonesia, Japan, the Lao PDR, Malaysia, Nepal, the Philippines, the Republic of Korea, Sri Lanka, and Viet Nam. Whereas in most cases plans and mechanisms are yet to be implemented, concrete commitment was reported by some countries. In this regard, Indonesia stands out in its approach to involve local stakeholders. Its SDG implementation approach is structured around four platforms, emphasizing the integration of defined stakeholder groups. The approach supports commitment and generates SDG dissemination at both the national and subnational levels. Other examples were reported by Japan, which actively engages local municipalities in incorporating SDG-related priorities into policies, and by Viet Nam, where SDGs are nationalized into an action plan that puts emphasis on partnerships and responsibilities at both the national and subnational levels. Also, Nepal reported on plans to mainstream the SDGs into local plans and programs, and highlighted (i) its commitment to the principle of "leaving no one behind" by eradicating poverty and (ii) the promotion of prosperity as well as the need for capacity building at the provincial and local levels. The Philippines mentioned in its VNR report the need to align national, provincial, and local plans. The Government of the Philippines'
National Economic and Development Authority and its regional offices have committed to empower local governments (through capacity building to enable the provision of dedicated resources, and the establishment of effective institutions), enabling them to incorporate the SDGs in local plans and policies. In Bhutan, awareness-raising efforts for local governments took place in 2016, and integration of the SDGs in the "Sector and Local Governments Key Results Areas" is being implemented. Bhutan's 12th Five-Year Plan, 20182023 prioritizes "livability, safety and sustainability of human settlements improved" as one of its National Key Results Areas, and a Nationally Appropriate Mitigation Action Plan on human settlements. The objective of the 12th Five-Year Plan, as mentioned in the VNR, is to achieve a "just, harmonious and sustainable society through enhanced decentralization."19

Framework legislation was initiated in Sri Lanka, where the National Sustainable Development Act, No. 19 of 2017 requires all levels of government to prepare sustainable development strategies and carry out reviews. The act provides the basis for establishing a legal, institutional, and strategic framework for implementing the 2030 Agenda and mainstreaming the SDGs at the local level, including actions such as public awareness campaigns, the establishment of local indicators for progress review, and the implementation of a sustainable development village program.

\section{Local and Regional Government Engagement in Consultation Processes}

About half of the 24 Asia and Pacific countries that carried out a VNR involved LRGs in their VNR consultation processes. These countries included Australia, Bhutan, Indonesia, Japan, Kiribati, Nepal, the Philippines, Sri Lanka, and Viet Nam; in Indonesia, local governments conducted consultations to launch regional action plans.

According to a survey carried out by Indonesia's national project for the localization of the SDGs, $95 \%$ of regional governments conducted consultations, and $40 \%$ of local governments have dedicated entities dealing with the SDGs, with several already having made commitments to implement the SDGs (footnote 18). In the Philippines, the results of local consultations helped to identify the key SDG priorities. A few countries, including Bangladesh and Sri Lanka,
Cities are making progress in designing and implementing policies, plans, and projects that enhance sustainable development.

\footnotetext{
19 Government of Bhutan. 2018. Sustainable Development and Happiness: Bhutan's VNR Report. Thimphu. p. 15.
} 
Awareness raising, communication

campaigns, and workshops took place in many of the Asia and Pacific countries that carried out a VNR. engaged members of their respective parliaments. Several consultations with members of Parliament were held in Bangladesh, which highlighted their instrumental role in transmitting and integrating the SDGs in local development initiatives.

\section{Local Initiatives and Sustainable Development Goal Plans}

Among others, the VNR reports of Bhutan, India, Indonesia, and the Republic of Korea featured examples of LRGs that have independently taken the lead on SDG implementation. Indonesia's report highlighted the commitment of several districts and municipalities to implement the SDGs. ${ }^{20}$ The report called attention to the challenges linked to SDG localization such as (i) defining a strategy to operationalize SDGs at the local level; and (ii) prioritizing the SDGs in local contexts, which requires policies, programs, and guidelines for local governments and other stakeholders.

Local governments in Indonesia, the PRC, and the Republic of Korea, among other countries, have taken steps to integrate the SDGs in their strategies. In its 2016 VNR report, the PRC mentioned progress on 31 subnational plans in accordance with its 13th Five-Year Plan, 2016-2020, ${ }^{21}$ which integrates the SDGs. ${ }^{22}$

The Republic of Korea reported on partnerships that help promote sustainable development efforts at the local level, and India indicated that several states had initiated aligning the SDGs and the development of road maps for implementation. Many reports include sector-based plans and specific programs that support local development: for example, the reports of Bhutan and Thailand include local disaster management plans, and Indonesia's report includes the development of sector plans in the area of fisheries management and marine protection.

\section{Awareness Raising at the Local Level} Awareness raising, communication campaigns, and workshops took place in many of the Asia and
Pacific countries that carried out a VNR, including in Australia, Bangladesh, Bhutan, Georgia, Indonesia, Japan, Kiribati, Nepal, New Zealand, the Philippines, the Republic of Korea, Sri Lanka, Thailand, and Viet Nam. In Viet Nam, for example, awareness raising and training activities were carried out to strengthen the capacity of local stakeholders in partnership with national and international institutions.

A number of countries emphasized the critical role of LRG associations in raising awareness, strengthening institutional and operational capacities, and building the commitment to include the SDGs in local and regional policy frameworks. For example, LRG associations in Australia, Indonesia, Kiribati, Nepal, New Zealand, Pakistan, ${ }^{23}$ the Philippines, the Republic of Korea, Sri Lanka, and Viet Nam carried out a variety of activities such as forming declarations, facilitating engagement in forums and national conferences, and training.

United Cities and Local Governments (UCLG) Asia-Pacific has been supporting efforts to localize SDGs in the region, including by implementing a nationwide project to localize SDGs in Indonesia, with newly elected local government officials as the main target of the project. The project consists of an awareness-raising campaign, capacity building for local government officials, and peer learning among local governments. The objective of the project is to mainstream the SDGs into a local planning document. Given the positive feedback received in Indonesia, UCLG Asia-Pacific intends to expand the project to involve more local governments in Southeast Asia, including using peer learning on best practices and lessons learned from other local governments in the region.

Some countries have developed knowledgesharing programs, publications, newsletters, and campaigns, or have promoted local plans aligned to the SDGs and engaged in the VNRs. For instance, the Local Sustainability Alliance of Korea provides a knowledge- and information-sharing platform for integrating the SDGs into policies and programs through its Local Commissions on Sustainable

20 Some of the districts and municipalities implementing the SDGs in Indonesia include Pangkajene Islands District (Pangkep) in South Sulawesi Province, Bojonegoro District in East Java Province, Kubu Raya District in West Kalimantan Province, Gunung Kidul District in Yogyakarta Province, and East Lampung District in Lampung Province. Their commitment is realized in various initiatives. For example, Bojonegoro District has established an SDG Secretariat and Pangkep District is preparing to formulate an SDG regional action plan that focuses on poverty, education inequalities or gaps, health, and marine ecosystems. Similar to Pangkep District, Kubu Raya District will focus on poverty, education, and health. Government of Indonesia, National Development Planning Agency. 2017. Voluntary National Review: "Eradicating Poverty and Promoting Prosperity in a Changing World." Jakarta. p. 7.

21 The PRC's 13th Five-Year Plan was reviewed and approved by the Fourth Session of the 12th National People's Congress in March 2016.

22 Government of the PRC. 2016. Voluntary National Review of the 2030 Agenda for Sustainable Development. Beijing.

23 Pakistan has not yet carried out a VNR, but efforts have been made to localize the SDGs. 
Development nationwide network, which it established in 2000. The network has been a vital institutional platform to ensure participation of local commissions in policy dialogues for the SDGs at the national level. In Viet Nam, a network of local and international nongovernment organizations, sociopolitical and socio-professional organizations, and an association for persons with disabilities have conducted activities to implement SDGs and have made direct contributions to the VNR. In the Philippines, local governments received government briefings through the Union of Local Authorities of the Philippines.

\section{Capacity and Financial Resources}

To enhance SDG localization, several countries, including Armenia, India, Indonesia, Nepal, and the Philippines, emphasized the need to strengthen the capacities of LRGs in relation to technical, data collection, monitoring, and financial capacities. In the Philippines, the National Economic and Development Authority and its regional offices have committed to empower local governments to incorporate the SDGs in local plans and policies and resources. The Government of Indonesia also reported on capacity building efforts and carried out trainings on mainstreaming the SDGs in provinces and districts and municipalities that are in the process of formulating development plans. The Government of Indonesia also ensured allocation of funds that support localization and reported on the development of a public spending advocacy model to reinforce local governments' poverty alleviation programs. It also highlighted the implementation of fiscal decentralization efforts through the provision of a special allocation fund that supports national priorities by funding local governments to provide general basic services in specific locations.

The need to financially empower communities was furthermore underscored in Armenia's VNR, which stated that local communities have limited own-revenue sources and depend heavily on financing from the central budget, which limits their ability to implement effective economic and social development.

\section{Data Collection and Monitoring at the Local Level}

Local statistical capacity to monitor and evaluate SDG progress was emphasized in the reports of (among others) Armenia, Georgia, Indonesia, the Lao PDR, Nepal, the Philippines, Thailand, and Viet Nam. Nepal, The Philippines, Thailand, and Viet Nam, underlined the need for statistical capacity building and mechanisms that strengthen disaggregated data collection efforts at the local level. Nepal reported on the approval of a resolution that encourages government agencies at the national and subnational and local levels to provide the necessary data support in monitoring the country's performance in relation to the SDGs. In Indonesia, some provinces have started local indicator development as a result of SDG capacity building training. Armenia highlighted the need for a sufficient level of data disaggregation at the local level, emphasizing the need for legal institutional arrangements and user-friendly data collection systems at the community level. Armenia's translation of SDG targets and indicators into local, community-level realities aims to increase stakeholder engagement in the SDG implementation process. In the Philippines, the League of Cities monitors progress on the achievement of various global commitments such as the SDGs. A system of (local target) scorecards is used to document baseline data for governance and whether development plans are aligned with the SDGs. Some cities are signing specific conventions with the Department of the Interior and Local Government to implement projects connected with the Sustainable Development Goals-Family-Based Actions for Children and their Environs in the Slums project (e.g., Mandaluyong City in Metro Manila). ${ }^{24}$

\section{Localization Approaches in the Context} of Sustainable Development Goal 11:

\section{Sustainable Cities and Communities} With a view to SDG 11, progress at the city level has been notable in the Asia and Pacific region. The VNRs illustrate that some metropolitan areas are moving fast in aligning their strategic plans with the SDGs. In particular, Australia, Indonesia, Japan, the Republic of Korea, and Singapore have reported considerable progress made on SDG 11. For instance, Jakarta is preparing a road map for the localization of the SDGs, whose indicators will be included in the city's medium-term development plan, 2018-2023. ${ }^{25}$ In Japan, a number of governmentsupported programs such as "Future City" and "Ecomodel City" specifically prioritize SDG 11. These programs involve 34 cities and towns that

\section{The VNRs}

illustrate that some metropolitan areas are moving fast in aligning their strategic plans with the SDGs.

\footnotetext{
24 Footnote 18 , p. 37

25 Footnote 18, p. 36
} 


\section{The VNRs}

\section{demonstrate that}

a limited number

of countries in the

region apply holistic

approaches that can

support the vertical

and horizontal

coherence embedded

in the 2030 Agenda. address common challenges and promote the creation of new values in environmental, social, and economic aspects. Kitakyushu city, Shimokowa town, and Toyama city launched voluntary local reviews (Box 3). ${ }^{26}$ In the Republic of Korea, the Seoul Sustainable Development Vision was adopted in 2014, including 12 strategies organized along the objectives of environment, society and culture, and economy. The vision was launched by the Sustainable Development Commission and was accompanied by the development of the Seoul Metropolitan City's Basic Plan for Sustainable Development and the adoption of the Seoul Metropolitan Government's Ordinance on Sustainable Development and the Seoul SDGs. ${ }^{27}$ In addition, Seoul hosted the International Forum on Urban Policy for the SDGs in 2016, which identified practical approaches and programs for sharing policy experiences, best practices, and innovative technologies among city stakeholders. In August 2018, the Korea Development Institute School of Public Policy in cooperation with regional development banks organized Localizing Sustainable Development Goals: The Role of Management for Development Results, an international seminar aimed at sharing practical cases of localizing the SDGs.

Singapore partnered with UN-Habitat on a capacity building program that aims to demonstrate how local development challenges can be overcome through applying sustainable urban system principles and long-term integrated master planning and development. Participants include mayors, city councilors, chief engineers, and other city leaders.

\section{What Is Needed to Further Localize the Sustainable Development Goals in Asia and the Pacific?}

Whereas the previous section illustrates that various local and subnational initiatives take place across the Asia and the Pacific region, further efforts to localize the SDGs will need to help accelerate the necessary progress on SDG implementation. Full alignment of the SDGs at all levels of government requires strong commitment to mainstream localization into SDG implementation, coordination, and legal frameworks. The VNRs demonstrate that a limited number of countries in the region apply holistic approaches that can support the vertical and horizontal coherence embedded in the 2030 Agenda. Whereas government structures and public management systems differ, it is critical that institutional and legal frameworks embody the integrated, cross-cutting nature of the 2030 Agenda at all levels of government.

Achieving policy coherence in a multilevel governance context has been a challenge in government reform processes for many decades. Decentralization modalities and approaches such as functional assignment processes offer solutions to how responsibilities and tasks within countries can be distributed so that different levels of sector administration cooperate and complement each other in pursuing the SDGs. ${ }^{28}$ Expenditure assignments can be adjusted to incentivize SDG implementation at the subnational level.

\section{Whole-of-Government Approach}

The benefits of effective interaction between and across levels of government are reflected in many VNRs. A common understanding is that moving toward a whole-of-government approach is instrumental for achieving the SDGs. This approach (i) entails moving away from fragmented and silo-based sector strategies to a holistic approach where vertical and horizontal collaboration helps build synergies between the SDGs; and (ii) requires bringing together relevant actors through, for example, participatory consultation, coordination, and implementation processes.

Whereas participatory consultation processes involving local stakeholders were carried out in a number of Asia and Pacific countries, further engagement of LRGs at all stages of the SDG implementation process is needed to effectively localize the SDGs. The task of fully engaging in and integrating the SDGs at the local level requires strong LRGs that are able to carry out functions such as SDG planning, monitoring and evaluation, fiscal administration, and service provision.

${ }^{26}$ Institute for Global Environmental Strategies. Sustainable Development Goals Report on Cities - Launch of SDG City Reports on Shimokawa, Toyama, and Kitakyushu. https://www.iges.or.jp/en/sdgs/report.html.

27 Seoul's Sustainable Development Vision includes a plan consisting of 12 strategies, 28 tasks, and 30 dedicated indicators to implement the international development agendas and review the impact on urban governance and activities. On 22 November 2017, the Seoul Metropolitan Government announced the Seoul Sustainable Development Goals. The goals embody Seoul's direction of development as a sustainable city with 17 major goals and 96 detailed targets.

28 R. Rohdewohld. 2017. Localizing Global Agendas in Multilevel Governance Systems: The Benefits of Functional Assignment as Core Element of Decentralization Reforms. The Governance Brief. No. 30. Manila: ADB. 
Several countries raised the need for reform and strengthening of capacities at the local level, particularly statistical and financial capacities.

\section{Local Data Collection and Monitoring Capacities}

Local statistical capacities to collect data, monitor, evaluate, and engage in national SDG-related data efforts are critical elements of the successful implementation of the SDGs. Although many of the Asia and Pacific countries that carried out a VNR recognize the need to strengthen statistical capacities and are committed to doing so, concrete steps are needed to actualize local data and monitoring initiatives. The SDGs will be monitored through a system of 232 indicators, many of which can be adapted to local contexts. Whereas questions surrounding localization and data disaggregation exist (e.g., understanding the costs and benefits for LRGs, as well as local variations of any SDG-related sector), ${ }^{29}$ experience shows that local SDG data and monitoring initiatives provide a platform for broad stakeholder engagement, which enhances inclusive SDG implementation. The strengthening of financial and technical capacities to develop accurate statistics and to disaggregate and collect indicators at all levels should therefore be promoted. Furthermore, it is critical to encourage participation of LRGs in national SDG monitoring activities and to promote adapting national indicators to local contexts. In addition, the following actions help provide structure to national and local SDG-related decision-making and strategic action: (i) developing localized indicators, (ii) ensuring that information collected by LRGs is included in national monitoring and reporting, (iii) enabling participation of LRGs and stakeholders in the review of national plans, and (iv) ensuring local achievements are recognized and part of the national SDG progress reports and the VNRs.

\section{Financial Capacities}

As pointed out by some countries that carried out a VNR, increasing responsibilities of LRGs to monitor and take on the necessary functions to ensure effective SDG localization requires adequate financial capacities. The need to strengthen institutional and fiscal frameworks to empower LRGs was similarly highlighted in the Financing for Development: Progress and Prospects 2018 report. ${ }^{30}$ The report assesses progress in implementing the Financing for Development outcomes and the means of implementation of the Sustainable Development Goals and the Addis Ababa Action Agenda. ${ }^{31}$ The report states that LRGs face challenges in mobilizing adequate revenues to meet recurrent expenditures and make long-term investments in support of inclusive and sustainable local development, and it highlights the need for a better understanding of financing options available to LRGs. In order to empower LRGs, the report underscores the importance of (i) strengthening of national and subnational institutional frameworks to include formal and clear assignment of functions and revenue generation responsibility; (ii) transparent and accountable financial management; (iii) incentives to function effectively; 32 and (iv) predictable and flexible intergovernmental transfers that (a) allow LRGs to respond to local needs and (b) contribute to global national and local development goals. Access to sustainable long-term finance, international public finance, commercial finance, and public-private partnerships can potentially help support LRGs secure expertise and funds to take on the responsibilities that come with SDG implementation. ${ }^{33}$

\section{Scaling Up Local Partnerships}

Apart from the institutional and financial framework that facilitates vertical coherence, key efforts that enhance horizontal coherence across sectors at the local level are of critical importance in view of SDG 17, target 17.14, which calls on countries to enhance policy coherence by, among other things, tapping into the benefits of synergetic actions among stakeholders and levels of government. While many $V N$ Rs reproduce a top-down vision on SDG implementation strategies, emphasizing the inclusion of national SDG priorities in local plans, few VNRs stress the need for scaling up local innovative actions and local priorities aligned with

29 M. Patole. 2018. Localization of the SDGs through Disaggregation of KPIs. Economies. 6 (15). pp. 1-11.

30 UN, Department of Economic and Social Affairs, Financing for Development Office. 2018. Report of the Inter-agency Task Force on Financing for Development-Financing for Development: Progress and Prospects 2018. New York.

31 UN, Department of Economic and Social Affairs, Financing for Development Office. 2015. Addis Ababa Action Agenda of the Third International Conference on Financing for Development. New York. Para. 34

32 E.g., to strengthen local financial and asset management systems and administer local taxes and fees.

33 UN, Department of Economic and Social Affairs, Financing for Development Office. 2018. Report of the Inter-agency Task Force on Financing for Development-Financing for Development: Progress and Prospects 2018. New York. p. 20. 


\section{A number of \\ networks have \\ emerged that provide \\ support and guidance \\ to SDG localization \\ based on the \\ partnership approach.}

\section{Box 4: Sustainable Development Goal Localization Partnerships and Platforms}

To support Sustainable Development Goal (SDG) localization, a variety of networks have initiated partnerships and platforms that provide guidance on bringing the SDGs to the local level. These include the following:

\section{Local2030}

Local2030 is a convergence point between local actors, national governments, and the United Nations (UN) system that supports the on-the-ground delivery of the SDGs. With a focus on the furthest behind, Local2030 seeks solutions and implementing strategies that advance the SDGs at the local level. A core feature of Local2030 is the network of local and thematic hubs, which constitute action-oriented and solution-oriented partnerships between the UN system and a wide range of stakeholders, including national governments, local and regional governments, banks and other financial bodies, businesses, civic institutions, and nongovernment organizations.

\section{Localizing the SDGs}

Localizing the SDGs was launched at the World Summit of Local and Regional Governments in 2016 by three partners: the Global Taskforce of Local and Regional Governments, the UN Development Programme, and UN-Habitat. The platform provides key tools and practices for local policy makers, development practitioners, and other actors to support countries in the implementation and achievement of the SDGs locally.

Source: P. D. Oosterhof. Presentation prepared for the 13th Decentralisation and Local Governance Annual Meeting. The Hague. May 2018. the SDGs in national strategies. Local public-private partnerships can support the mainstreaming of interlinkages and synergies between the SDGs at the local level. A number of networks have emerged that provide support and guidance to SDG localization based on the partnership approach (Box 4).

\section{Conclusion}

To accelerate the implementation of the SDGs and sustain it beyond 2030, strong vertical dialogue and collaboration to localize and align the SDGs is required. Localization can be a key driver in tackling the critical challenges faced by countries and communities in Asia and Pacific, which include rapid urbanization, growing inequalities, and the impact of climate change and disasters.

The VNRs illustrate that some efforts to localize the SDGs, specifically in regard to SDG 11, have taken place in the Asia and Pacific region since the SDGs were launched in 2015. However, a holistic approach to localization is often absent in the SDG planning, coordination, and implementation processes of national governments in the region. A stronger push for promoting policy coherence, multilevel governance, and the concept of localizing the SDGs is required to make progress on achieving the SDGs.
Building on the lessons learned from implementing the MDGs. The 2030 Agenda is inclusive and transformative, requiring structures and enabling environments that fully embrace subnational and local contributions. Installing a public management approach that promotes a whole-of-government approach and emphasizes vertical and intersectoral integration can help facilitate SDG localization. For this purpose, mechanisms that support the alignment of national and local sustainable development agendas must be in place. The institutional mechanisms must have a coordinating, integrating, and monitoring and evaluation function that includes LRGs and strengthens SDG ownership at the local level. At the national level, this requires commitment, advocacy, and continuous support for local governance as well as national policy and legal frameworks that integrate local SDG plans. At the local level, effective localization requires, first and foremost, awareness of the SDGs. Awareness raising can facilitate a clear understanding of the link between local and global goals and vice versa. Translating the SDGs into local contexts is needed to define where LRGs and local stakeholders can contribute to-and how communities can benefit from-achieving the SDGs. LRGs can prepare to implement the SDGs in their communities by, for example, conducting needs assessments, aligning local plans with the 
SDGs, mobilizing local resources, building capacities for effective and responsive leadership, promoting ownership, and monitoring progress. Local SDG implementation efforts should build on the synergies between SDGs in the form of partnerships and cross-cutting programs. The inclusion of LRGs in the VNR processes, and in the follow-up and coordination frameworks, is a particularly important step in localizing the SDGs.

Even though LRGs and cities are on the front line of addressing global sustainable development challenges, many lack adequate resources and capacity to take on the functions required to effectively localize the SDGs (particularly strengthened planning, and financial and data management capacities). Local data collection, disaggregation, and analysis can enable a better understanding of the local realities and the needs of vulnerable groups. Local data collection and monitoring can significantly contribute to reducing inequalities and the 2030 Agenda's principle of "leaving no one behind."

Overall, the 2030 Agenda for Sustainable Development is a unique opportunity to rethink public management and local development. Without localizing the SDGs, much progress on implementation of the SDGs will be left untapped.

This governance brief was peer-reviewed by Rainer Rohdewohld, independent senior policy advisor Decentralization and Public Sector Management, and Edgardo Bilsky, director of research, United Cities and Local Governments.

\section{References}

- Global Taskforce of Local and Regional Governments, UNDP, UN-Habitat. 2016. Roadmap for Localizing the SDGs: Implementation and Monitoring at Subnational Level. Barcelona.

- Institute for Global Environmental Strategies. 2018. Shimokawa Town the Sustainable Development Goals Report 2018. Kanagawa, Japan.

- Institute for Global Environmental Strategies. 2018. Toyama City the Sustainable Development Goals Report 2018. Kanagawa, Japan.

- Institute for Global Environmental Strategies. 2018. Kitakyushu City the Sustainable Development Goals Report 2018. Kanagawa, Japan.

- Organisation for Economic Co-operation and Development. 2018. Policy Coherence for Sustainable Development 2018: Towards Sustainable and Resilient Societies. Paris.

- M. Patole. 2018. Localization of the SDGs through Disaggregation of KPIs. Economies. 6 (15). pp. 1-11.

- R. Rohdewohld. 2017. Localizing Global Agendas in Multilevel Governance Systems: The Benefits of Functional Assignment as Core Element of Decentralization Reforms. The Governance Brief. No. 30. Manila: ADB.

- P. Stephenson. 2013. Twenty years of multi-level governance: "Where Does It Come From? What Is It? Where Is It Going?" Journal of European Public Policy. 20 (6). pp. 817-837.

- UCLG. 2017. Local and Regional Governments' Report to the 2017 HLPF: National and Sub-National Governments on the Way Towards the Localization of the SDGs. Barcelona.

- UCLG. 2018. Local and Regional Governments' Report to the 2018 HLPF-2nd Report: Towards the Localization of the SDGs. Barcelona.

- UN. 2008. Highlevel event on the Millennium Development Goals. Committing to action: achieving the Millennium Development Goals. Background note by the Secretary-General. New York.

- UN, Department of Economic and Social Affairs, Financing for Development Office. 2015. Addis Ababa Action Agenda of the Third International Conference on Financing for Development. New York.

- UN, Department of Economic and Social Affairs, Financing for Development Office. 2018. Report of the Inter-agency Task Force on Financing for Development-Financing for Development: Progress and Prospects 2018. New York. 
Box continued

- UN, Department of Economic and Social Affairs. 2018. Handbook for the Preparation of Voluntary National Reviews: The 2018 Edition. New York.

- UN, Department of Economic and Social Affairs. Voluntary common reporting guidelines for voluntary national reviews at the high-level political forum for sustainable development (HLPF).

- UN, Department of Economic and Social Affairs. 2018. World Public Sector Report 2018-Working Together: Integration, Institutions and the Sustainable Development Goals. New York.

- UN Development Group. 2014. Localizing the Post-2015 Agenda: Dialogues on Implementation. New York.

- UN Development Group. 2013. The Global Conversation Begins: Emerging Views for a New Development Agenda. New York.

- UNDP and World Bank Group. 2016. Transitioning from the MDGs to the SDGs. New York and Washington, DC.

- UN Economic and Social Commission for Asia and the Pacific. 2018. Asia and the Pacific SDG Progress Report 2017. Bangkok.

- UN General Assembly. 2016. UN Resolution 70/A/684: Critical milestones towards coherent, efficient and inclusive follow-up and review at the global level. New York.

- UN General Assembly. 2015. UN Resolution 70/1: Transforming our world: the 2030 Agenda for Sustainable Development. New York.

- UN, Department of Economic and Social Affairs. Sustainable Development Knowledge Platform. High-Level Political Forum on Sustainable Development. Voluntary National Reviews Database.

Creative Commons Attribution 3.0 IGO license (CC BY 3.0 IGO)

(C) 2018 ADB. The CC license does not apply to non-ADB copyright materials in this publication.

https://www.adb.org/terms-use\#openaccess

ISBN 978-92-9261-448-5 (print), 978-92-9261-449-2 (electronic)

ISSN 2520-6591 (print), 2520-6605 (electronic)

Publication Stock No. BRF189612 http://www.adb.org/publications/corrigenda

pubsmarketing@adb.org

https://www.adb.org/publications/series/governance-briefs

DOI: http://dx.doi.org/10.22617/BRF189612

Note: ADB recognizes "Korea” as the Republic of Korea. 